\title{
How can cities lead the way towards a sustainable, competitive and smart future?
}

\author{
T. Monfaredzadeh ${ }^{1} \&$ U. Berardi ${ }^{2}$ \\ ${ }^{1}$ Regional and Urban Studies and Planning Department, \\ Politecnico di Torino, Italy \\ ${ }^{2}$ Civil \& Environmental Engineering Department, \\ Worcester Polytechnic Institute (WPI), USA
}

\begin{abstract}
As dramatic social and technological changes are occurring, cities around the world are facing the challenge of reconciling immediate competitiveness and long-term sustainability. The Smart City concept has received increasing attention as a new paradigm for sustainable growth. However, smartness and sustainability may have only some common aspects. A Smart City does not necessarily have to be a city which develops in a sustainable way. In particular, there is a dichotomy within the concept of Smart City between the goals of competitiveness and sustainability. This paper compares sustainability indicators and smart/competitive indicators for cities to find out when they complement or contrast. The scope is to investigate the conditions in which the smartness of a city can guarantee its being sustainable, competitive, or simply smart.
\end{abstract}

Keywords: sustainability, Smart City, Competitive City, assessment, rating systems.

\section{Introduction}

In recent decades, urbanization (the demographic transition from rural to urban along with a shift from agriculture to mass industry) has significantly affected the growth of cities worldwide. By $2009,50 \%$ of the world population lived in urban areas and this growing trend is expected to continue in the coming decades, reaching nearly $70 \%$ in 2050 (UN [1]).

Cities, as the home to most of the world's population and intellectual and economic capital, are at the forefront of progress for citizens and are very 
important actors for environmental sustainability. Amid profound economic, social, and technological changes, cities around the world are facing the challenge of reconciling the needs of immediate competitiveness with long-term sustainable development (Caragliu et al. [2]). As much as cities nowadays need to have a specific sustainable plan which targets relevant environmental problems, they also need to find ways to revitalize economic opportunities and to strengthen their global competitiveness. Cities have positive impacts on the economic and social aspects of sustainability, but not on the environmental ones (Mori and Christodoulou [3]). From one side, economic growth increases a city's ability to attract capital, business, talent, and visitors. From the other side, as the city gives more services, it uses more resources and pollutes more. Past economic development has been characterized by the depletion of resources and has resulted in the pollution of the environment, with most scholars agreeing that we cannot continue forever in this manner, because pollution and depletion will result in serious consequences for future development (Homer-Dixon [4]). Therefore, concerns are rising among policy makers and city authorities about their plans and initiatives for approaching sustainable criteria and future improvements in city services.

Generally, it seems that there is a dichotomy between the issues of sustainability and competitiveness. Considering that both targets are included in most cities agenda, it is useful to investigate the two concepts together to explore the possible ways in which cities approach both.

The practice of sustainable urbanization plays an important role in achieving global sustainability targets. In line with the promotion of sustainable urbanization, international institutions and governments at different levels are seeking urban sustainability characteristics. With the aim of assessing the changes to better urban sustainability performance, sets of indicators, frameworks and assessment tools have been developed. Urban sustainability indicators are crucial for helping on target setting, performance reviews and facilitating communication among the policy makers, experts, and public. A wide range of urban sustainability indicators is therefore in use across cities and regions, which vary according to their particular needs and goals (Brandon and Lombardi [5]).

On the other side, competitiveness is a holistic concept. Economic growth matters, but several other factors determine city competitiveness too; including its business and regulatory environment, its institutions, the quality of human capital, cultural aspects, and the quality of governance. These factors sustain economic growth and secure its future competitiveness (Economist Intelligence Unit [6]).

The concept of Smart City, which has become very popular these days (Albino et al. [7]), is based on the adoption of ICT (Information and Communication Technologies) as ways to revitalize economic opportunities and to increase global competitiveness. Smart initiatives range from small-scale applications of individual technologies to ambitious projects aiming to transform entire urban areas through master planning and infrastructure development (Lee et al. [8]).

There are many definitions of smart cities (Albino et al. [7]). Some focus on ICT as a technology driver and enabler, while broader definitions include socioeconomic, governance, and multi-stakeholder aspects such as the use of social 
participation to enhance sustainability, quality of life, and urban welfare. In any case, a Smart City is mainly enabled by the use of technologies (especially ICT) to improve competitiveness and ensure a more sustainable future by symbiotic linkage of networks of people, businesses, technologies, infrastructures, consumption, energy, and spaces (EU [9]).

The purpose of this paper is to review what the Sustainable City, Smart City, and Competitive City seek to achieve. The rating systems defined for assessing each concept are compared to find where they are mutually complementary or where they are in conflict. The city scale is chosen to be the base of analysis. Cities should be the object of closer scrutiny since the majority of developed economies' population live in cities and are the source of many sustainable development related problems such as pollution, crime, and housing (Thomas [10]).

In section 2, the methodology for choosing the sustainable indicator systems is introduced and the strategy for selecting the indicators covering the sustainable development components is proposed. In section 3 , the indicators and indices defined to assess Competitive and Smart City concepts are described. In section 4, the categorization of the indicators related to the three concepts is presented. Section 5 allows finding common points and differences between concepts. Concluding remarks are made in section 6.

\section{Sustainable City rating systems}

This section investigates indicators of sustainable development focusing on the issues the indicators cover and the fields they study. The way in which the measurements are done is not examined below.

\subsection{Methodology for the selection of systems}

Today, a variety of sustainability indicator systems are in use or development. There are as many possible interpretations or approaches to the creation of sustainable development as there are of its indicators (Berardi [11]). Similarly, depending on the objectives for the use of indicators, the approach varies among studies (Tanguay et al. [12], Berardi [13]).

18 systems that apply indicators related to sustainable development were investigated. The applicability of the systems to the city scale was primarily considered. Systems created to be applied to one specific city, or in the context of one province or state, were excluded because the interpretation of sustainability may be very limited. Understanding the scale of identified systems is particularly important as this influences the selection of indicators (Lynch et al. [14]).

The other factor which was considered in selection of the systems was the type of the organizations that have released them. Institutional, non-profit/NGO, private/public organizations, and national/international systems follow a variety of approaches toward sustainability with a broad list of indicators. 
The initiation time of the indicator system was also considered. As the issues and problems related to sustainability may differ with the time, systems which were initiated before the year 2000 were excluded. Systems were examined to have actual indicators instead of general goals, or benchmarks. The degree of implementation and application in real cases also were observed. Some systems were merely theoretical and were eventually excluded.

After the application of aforementioned conditions, a list of 11 indicator systems was created as shown in table 1 . This list of systems is not comprehensive, but it should be considered as representative of a variety of important existing systems including different organizations, methodologies, scales, and evaluation methods.

\subsection{Compiling a database of indicators}

For the selection of the indicators related to the systems updated in table 1, the following three steps were taken:

1) A list of all indicators used in the 11 systems was compiled. The initial scan yield a list of 428 indicators; these were then reduced to exclude indicators overly broad (e.g. food systems in Estidama) or very specific (e.g. minimization of greenhouse gas generation and exposure to localized air pollutants during landscape maintenance in Sustainable Sites Initiative), or not generic for all sustainable cities (e.g. percentage of area of assessed rivers and streams that do not meet state and federal water quality standards in Green Communities).

2) Duplicate indicators were combined. In the initial list of indicators there were many indicators which were evaluating different aspects of the same subject. For example "the number of personal automobiles per capita" and "the percentage of trips by motorized private transport" both intend to measure the use of private cars in city. The indicators were merged into a single one: "use of private car in transport".

3) The indicators were classified in a thematic layout of nine sustainable dimensions: natural environment, built environment, transportation, energy, economy, wellbeing and health, education and culture, water and waste management, and governance. Two categories of innovation and equity were also defined in the first phase. However, as the systems had provided just general goals and not actual indicators in these two fields, they were eliminated. Previous categories were chosen according to both the structure of the systems and the requirements of a sustainable city. However, the organization of indicators into fully separated categories resulted in some difficulties as some indicators could be classified in more than one field. Also, the fields by themselves may have some overlaps. For example, the distinction of criteria for energy and natural environment was not always straightforward; this is exemplified by the urban heat island, an issue related to both the energy sector and the built environment. 
Table 1: Summary of the sustainability assessment systems studied in this paper.

\begin{tabular}{|l|l|c|c|}
\hline$\#$ & \multicolumn{1}{|c|}{ Indicator System } & \multicolumn{1}{|c|}{ Time of Initiation } & $\begin{array}{c}\# \\
\text { Ind. }\end{array}$ \\
\hline 1 & The Environmental Performance Index (EPI) & $\begin{array}{c}2000(2014 \text { last } \\
\text { version) }\end{array}$ & 25 \\
\hline 2 & STAR Community Rating System & $\begin{array}{c}2007 \text { (2013 last } \\
\text { version) }\end{array}$ & 48 \\
\hline 3 & Global City Indicators & 2008 & 63 \\
\hline 4 & Sustainable Sites Initiative & 2005 & 66 \\
\hline 5 & European Common Indicators & 2001 & 10 \\
\hline 6 & European Green City Index & 2009 & 30 \\
\hline 7 & Estidama & 2007 & 65 \\
\hline 8 & The UN Indicators of Sustainable Development & $2002(1 a s t$ & 50 \\
\hline 9 & The Ursion 2007) & \\
\hline 10 & Green Communities & 2010 & 18 \\
\hline 11 & Indicators for Sustainable Development Goals & 2008 & 40 \\
\hline
\end{tabular}

Similarly, the issues related to water-shed management could be considered to fall under both the water management and natural environment categories. It is important to remember that the classification of the indicators aimed to allow an easier comparison between sustainable and smart criteria. As long as the indicators were included in the list, the uncertainties were expected to have minimal impact on the result.

Applying the above process to the initial list of indicators reduced the number in the database by more than $60 \%$. Of the 146 remaining indicators, 21 related to natural environment, 13 related to the built environment, nine covered transportation, 20 related to energy, 20 were economic, 28 were in wellbeing and culture, five were in education and culture, 18 in water and waste management and 12 in governance and institution.

\section{Smart and Competitive City rating systems}

Despite its apparent novelty, the concept of smart cities was coined in the early 1990s. Gibson et al. [15] anticipated a kind of urban-tech phenomenon to come that would contribute to the enhancement of the quality of life as well as widen the range of global marketplaces. The authors' vision was that academia, together with governments and industry, would present information, ideas, programs, and initiatives in a new manner, more technological and informed than previously, that would accelerate the creation of fast systems and global networks.

In 2004, the concept of the digital city or e-city appeared, focusing more on the idea of a "connected community," combining broadband communications with 
government open data and open industry standards as a way to enhance the quality of life of "e-citizens" (Craglia [16]). Despite its earlier development, the smart cities concept has only became widely known recently, although it is still a somewhat fuzzy idea (Marsal-Llacuna et al. [17], Albino et al. [7]). Various studies have been conducted concerning the monitoring of the Smart Cities initiative. Caragliu et al. [2] have used the EU Urban Audit dataset to analyze the factors determining the performance of Smart Cities. They found that the presence of a creative class, attention to the urban environment, level of education, multimodal accessibility, and the use of ICTs for public administration are positively correlated with urban smartness. More interested in summarizing indices than working with a set of indicators, Malek [18] studied the suitability of an existing index, the Informative Global Community Development Index (IGC), for monitoring the Smart Cities initiative.

Interpretations of smart cities have originated from liveable, creative, digital, and knowledge cities, drawing heavily on the concept of the Sustainable City (Marsal-Llacuna et al. [17]). They aim to resolve various urban problems (public service shortages, traffic, over-development, pressure on land, environmental or sanitation shortcomings, and other forms of inequality) through ICT-based technology connected as urban infrastructure. Smart cities are envisioned as creating a better, more sustainable city, in which people's quality of life is higher, their environment is more liveable and their economic prospects are stronger (Lee et al. [8]).

Some programs exist to define smart indicators. They are often classified by clusters: smart people, smart environment, smart economy, smart living, smart governance, and smart mobility (Giffinger et al. [19], EU [9]). Triple Helix of the Smart Cities (Leydesdorff and Deakin [20]) is one of the models used for generating smart indicators. This has recently emerged as a reference framework for the analysis of knowledge-based innovation systems. This model relates the multiple and reciprocal relationships between the three main agencies in the process of knowledge creation and capitalization: university, industry, and government (Etzkowitz [21]). It provides a set of metrics and indicators to evaluate the smartness in the cities.

In recent time, many different rankings have been proposed as a tool for influencing national and international policy debates (Meijering [22]) and to contribute to the evaluation and development of urban policy. European Smart Cities Ranking (Giffinger et al. [19]) is one of these programs. It identifies the strengths and weaknesses of medium-sized cities and their perspectives for development in a comparative way and intends to help them to be equipped in terms of resources, and organizing capacity.

Proposing a set of indicators, Cities of Opportunity [23] and Hot Spots 2025 (Economist Intelligence Unit [6]) are ranking systems that intend to measure the competitiveness of cities. Cities of Opportunity involves cities that have the three factors of being capital market centers, broad geographic sampling, and having mature or emerging economies.

The effort was choosing the systems that measure cities with different scales. In this regard, as European Smart Cities Ranking deals with the medium-sized 
cities, the main focus of cities of opportunity tends to be on the 'global' metropolises. In Hot Spots 2025, there is no major correlation between a city size and its competitiveness ranking as densely populated small city-states such as Singapore and Hong Kong are thought to be among the most competitive places in 2025 (Economist Intelligence Unit [6]).

Observing four above introduced systems, a number of 266 indicators was collected of which 103 related to Competitive City and 163 to Smart City.

\section{The classification of the indicators}

After the compilation of the lists of indicators related to Sustainable, Smart, and Competitive City, all of the indicators were classified once in sustainable and another time in smart categories. In other words, all of the indicators were classified according to the structure of Sustainable City and Smart City rating systems. The Competitive City systems did not have a specific structure; therefore the indicators were not classified in competitive categories.

The first classification was based on categories of sustainability: natural environment, built environment, transportation, energy, economy, wellbeing and health, education and culture, water and waste management, and governance. The second classification included the main categories of the Smart City: smart people, smart environment, smart economy, smart living, smart governance, and smart mobility (Figure 1).

Figure 2 clarifies in which items the three concepts are mainly complementary and in which others have least similarities. The number of indicators in each sustainable field of study, the main items studied in individual fields, and the number of indicators which covers relevant and non-relevant issues are also shown. The implemented strategy made the comparison more observable and also generated noticeable differences among the systems' approaches.

\section{Comparison}

Figure 1 displays the structure of each three concepts and the way they have distributed their indicators in different groups. It reveals that there is a remarkable difference in the distribution of indicators in categories of one system with another. Each concept has emphasized a particular theme more than others: Sustainable City emphasizes more on environmental issues such as "energy" and "water management"; Smart City focuses more on "people" and "living"; and Competitive City involves mainly with "economy and business".

According to Figure 1, in many cases there are conflicts or sometimes dichotomies between the strategies one system applies with the other system's goals. As an example, the Sustainable City in concept intends to decrease private transportation, unnecessary urban travel, pollution, traffic congestion, and aims to increase sustainability in transportation. The Competitive City systems measure issues like "cost of the mass rail or bus trip" or "cab rates" or "direct links from airport to central business district with fewer transfers" which are all items that facilitate doing business in cities. The final goal is increasing services and their 
efficiency in order to make cities more attractive to investors and global visitors in order to create more jobs and revitalize the economy. So even if the number of indicators that consider the issue of transportation may be comparable in the two concepts, their approaches and final goals not only are not similar, but also are in conflict. A similar dichotomy exists in the field of "transport". Air travel is the least sustainable means of transport (Johansen [24]) that generates a great amount of carbon emission. In Competitive City, a high number of air travels to and from the city is positive and considered as a way of increasing city connections globally.
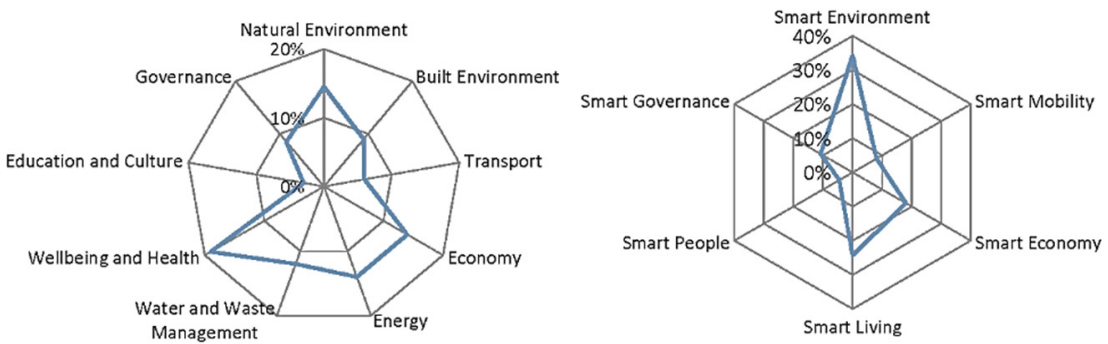

a. Sustainable indicators in Sustainable categories

b. Sustainable indicators in Smart categories
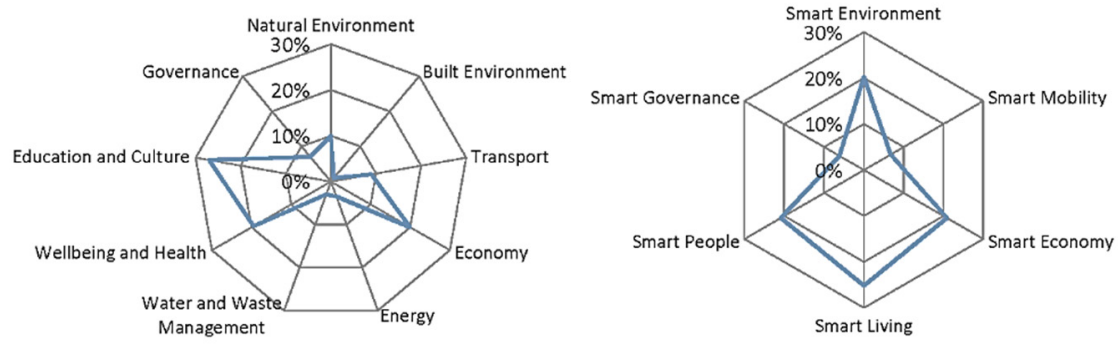

c. Smart indicators in Sustainable categories

d. Smart indicators in Smart categories

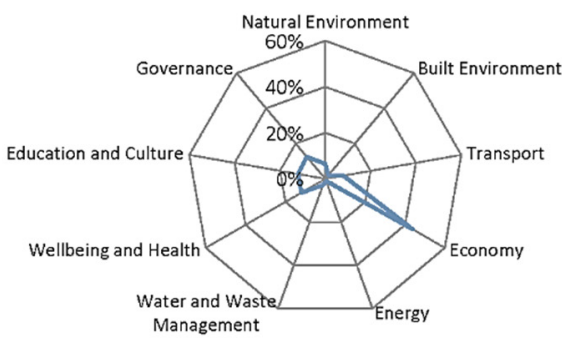

e. Competitive indicators in Sustainable categories

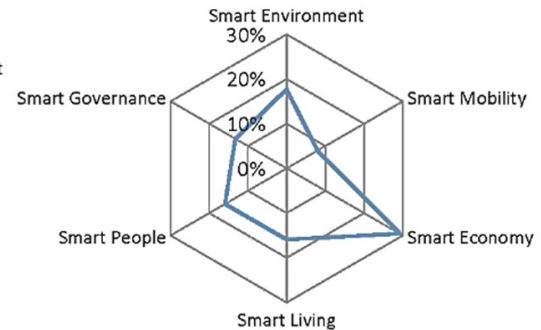

f. Competitive indicators in Smart categories

Figure 1: Distribution of indicators in sustainable and smart categories. 
As the categories of Smart City concept seem to be more distinguishable with fewer overlaps, applying this classification to the indicators of Sustainable City reveals that there are very few indicators dedicated to people (Fig. 1b). The role of people is underestimated and there is a scarcity in sustainable attributes that directly address people in society. This issue is still observable in the field of "education and culture", which is the most relevant field to people and society (Fig. 1a).

Smart indicators have rarely addressed issues related to "water and waste management" and "built environment" (Fig. 1c). That indicates that in the field of "smart environment", Smart City systems have emphasized mostly the virtual and human environment rather than the physical one. The European Union [9] includes the following topics in "smart environment":

"Smart energy including renewables, ICT enabled energy grids, metering, pollution control and monitoring, renovation of buildings and amenities, green buildings, green urban planning, as well as resource use efficiency, re-use and resource substitution which serves the above goals. Urban services such as street lighting, waste management, drainage systems, and water resource systems that are monitored to evaluate the system, reduce pollution and improve water quality ..."

According to this statement, it seems that there are several missing issues in smart systems which had to be observed by the indicators.

Referring to Figure 1, the classification of indicators in categories of Smart City, has created more homogeneous trends. This difference is caused due to the nature of categories that the two concepts have defined. Smart categories seem to be more adjusted and equal while the main categories of Sustainable City systems are different in values or have overlaps. For example the category of "water and waste management" seems to be very specific in comparison with "natural environment"; or the field of "energy" may have some overlaps with "natural environment". Among all circle charts, the least homogeneous trend belongs to the indicators of Competitive City in categories of Sustainable City (Fig. 1e). It proves that these two concepts have the most different approaches and the least in common for defining their goals and strategies.

Figure 2 shows the distribution of the indicators in each Sustainable City concept's category. The charts indicate the main topics that systems have covered and the number of indicators that they have allocated to uncommon items.

According to Figure 2, there are many commonly considered topics in the fields of "economy" (Fig. 2f), "education and culture" (Fig. 2g) and "wellbeing and health" (Fig. 2i). Although the number of uncommon indicators is still very high: as an example Competitive City has measured numerous topics in the field of "economy" that the other two systems have not covered. Comparably, in the field of "education and culture", Smart City indicators consider many issues which are not studied by the other two concepts. In the field of "governance" also, systems have studied very different items (Fig. 2d). The number of indicators allocated to different fields is noticeable in the diagrams. While the numbers of indicators in the field of "governance" or "transport" are close and comparable, there is a great difference in the fields like "water and waste management" or "energy". 
Figure $2 \mathrm{f}$ indicates how the issue of "housing" is emphasized by Smart City indicators, while it is not even observed in competitive ones. This is noticeable that "housing" is underestimated by Competitive City while "the number of hotel rooms" which seems to be more secondary is considered. A similar type of dichotomy exists in the fields of energy in Figure 2e. In this field Competitive City has defined only one indicator which concerns thermal comfort, while other important topics like energy consumption are ignored.

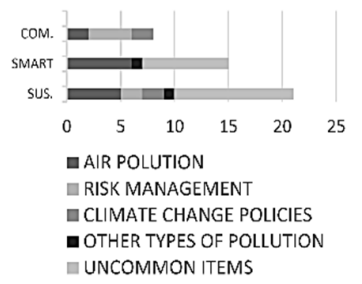

a. Number of indicators in the field of Natural Environment

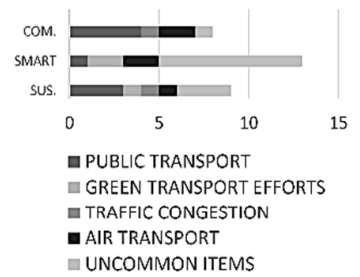

d. Number of indicators in the field of Transport

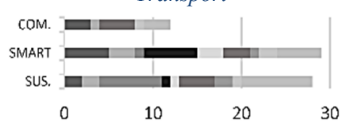

G HEALTH SYSTEM

MENTAL HEALTH

$\square$ DISEASE AND DEATH

- HOUSING

$\square$ POVERTY

$\square$ SAFETY

ICT ACESS

$\square$ ACCESS TO RECREATION FACILITIES

$\square$ UNCOMMON ITEMS

g. Number of indicators in the field of Education and Culture
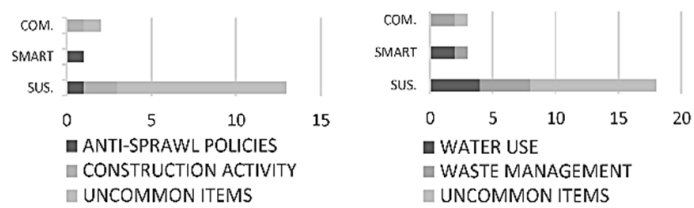

b. Number of indicators in the field of Built Environment

c. Number of indicators in the field of Water and Waste Management
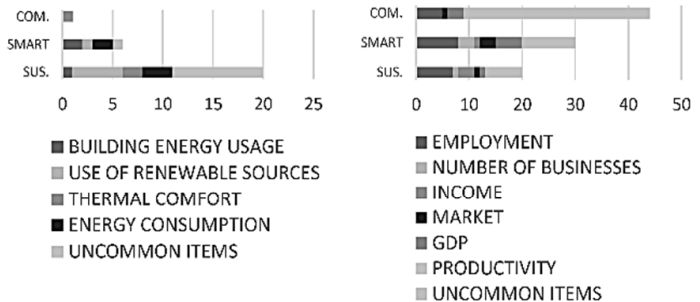

e. Number of indicators in the field of Energy

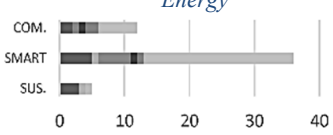

- EDUCATED PEOPLE

I POPULATION IN VOLUNTRAY WORK

$\square$ RESEARCH

- NUMBER OF LIBRARIES

- OPEN-MINDEDNESS AND CULTURAL VIBRANCY

— UNCOMMON ITEMS

Figure 2: Number of indicators related to each system in sustainable fields.

\section{Conclusions}

As cities must face the challenge of simultaneously combining competitiveness and sustainable urban development, conflicts in their goals are emerging. This paper primarily underlines the need to measure Sustainability, Smartness and Competitiveness of cities based on indicators or evaluation criteria. 
For each of these concepts, various systems of indicators have been studied and subsequently indicators according to the target of being sustainable or smart have been classified. Systems have also been compared according to the distribution of their indicators in each sustainable field. This comparison made the common topics studied in each system more evident. It presented a number of factors that helps to characterize a city to be competitive, smart, and sustainable. Eventually the conflicts and dichotomies that exist in approaching all targets were exemplified.

The paper stresses the need for a multi-dimensional view toward urban issues. Monitoring different rating systems reveals the weaknesses and strengths of the concepts they are defined for. The study proves that approaching one goal can makes complications toward reaching the other one. As long as different approaches and concepts are not studied together, these complications will not become evident. The next step is identifying how to solve these difficulties.

Further researches on this field should observe real case studies to find how these conflicts can be managed and resolved when cities implement strategies and initiatives with different targets and goals.

\section{References}

[1] UN, World urbanization prospects: the 2009 revision, UN Habitat: New York, pp. 51-52, 2010.

[2] Caragliu, A., Del Bo, C. \& Nijkamp, P., Smart cities in Europe, Journal of Urban Technology, 18(2), pp. 65-82, 2009.

[3] Mori, K. \& Christodoulou, A., Review of sustainability indices and indicators: Towards a new City Sustainability Index (CSI), Environmental Impact Assessment Review, 32, pp. 94-106, 2012.

[4] Homer-Dixon, T., Environment, scarcity and violence, Princeton University Press: Princeton, pp. 3-11, 2001.

[5] Brandon, P. S. \& Lombardi, P., Evaluating sustainable development in the built environment, Wiley-Blackwell: Oxford, pp. 73-87, 2011.

[6] Economist Intelligence Unit (EIU), Hot spots 2025: benchmarking the future competitiveness of cities, 2013.

http://www.citigroup.com/citi/citiforcities/home_articles/n_eiu_2013.htm.

[7] Albino, V., Berardi, U. \& Dangelico, R., Smart cities: definitions, dimensions, performance and initiatives, Journal of Urban Technology, $\mathbf{5 0 ( 6 ) ,} 2014$.

[8] Lee, J., Hancock, M. \& Hu, M., Towards an effective framework for building smart cities: Lessons from Seoul and San Francisco, Technological Forecasting and Social Change, 2013. doi: 10.1016/j.techfore.2013.08.033.

[9] European Union, Mapping smart cities in the EU, 2014. http://www.europarl.europa.eu/RegData/etudes/etudes/join/2014/507480/I POLITRE_ET(2014)507480_EN.pdf.

[10] Thomas, P-Y., Mesurer le de’veloppement durable en Belgique: Quel ro^le pour les processus participatifs? Research paper for the Conseil fe'de' ral 
du de'veloppement durable, Institut pour le de'veloppement Sustainable (IDD) and the Centrum voor duurzame ontwikkeling (CDO), 2003.

[11] Berardi, U., Clarifying the new interpretations of the concept of sustainable building, Sustainable Cities and Society, 8, pp. 72-78, 2013.

[12] Tanguay, G., Rajaonson, J., Lefebyre, J. \& Lanoie, P., Measuring the sustainability of cities: an analysis of the use of local indicators, Ecological Indicators, 10, pp. 407-418, 2010.

[13] Berardi, U., Sustainability assessment of communities through rating systems, Environment, Development and Sustainability, 15(6), pp. 1573-1591, 2013.

[14] Lynch, A., Anderson, S., Eisenman, Robinson, J., Steif, K. \& Birch, E., Sustainable urban development indicators for the US, PENN Institute of Urban Research, 2011.

[15] Gibson, V., Kozmetsky, G. \& Smilor, R., The technopolis phenomenon smart cities, fast systems, global networks, Maryland: Rowman and Littlefield, 1992.

[16] Craglia, M., Leontidou, L., Nuvolati, G. \& Schweikart, J., Towards the development of quality of life indicators in the 'digital' city, Environment and Planning B: Planning and Design, 31, pp. 51-64, 2004.

[17] Marsal-Llacuna, M., Colomer-Llinàs, J. \& Meléndez-Frigola, J., Lessons in urban monitoring taken from sustainable and liveable cities to better address the Smart Cities initiative, Technological Forecasting and Social Change, 2014. doi: 10.1016/j.techfore.2014.01.012.

[18] Malek, J. A., Informative global community development index of informative Smart City, WSEAS Transactions on Information Science and Applications, 7(1), pp. 112-121, 2010.

[19] Giffinger, R., Fertner, C., Kramar, H., Kalasek, R., Pichler-Milanović, N. \& Meijers, E., Smart cities: ranking of European medium-sized cities, Centre of Regional Science (SRF), Vienna University of Technology, 2007. http://www.smartcities.eu/download/smart_cities_final_report.pdf.

[20] Leydesdorff, L. \& Deakin, M., The Triple Helix Model and the MetaStabilization of Urban Technologies in Smart Cities, 2010. arXiv:1003.3344.

[21] Etzkowitz, H., The triple helix: university, industry and government, London: Routledge, pp. 1-7, 2008.

[22] Meijering, J., Kern, K. \& Tobi, H., Identifying the methodological characteristics of European green city rankings, Ecological Indicators, 43, pp. 132-142, 2014.

[23] Cities of Opportunity, Price water house Coopers (PWC), 2012. http://www.pwc.com/us/en/cities-of-opportunity/

[24] Johansen, B., Global warming in the 21st century, Praeger Publishing: Westport, 3, pp. 677-679, 2006. 